\title{
Feasibility of flow cytometric analysis of restricted light chain in endoscopic biopsy specimens from patients with gastrointestinal tract B cell lymphoma: a pilot study
}

\author{
Katsunori Matsueda ${ }^{1 *}$, Masaya Iwamuro ${ }^{1}$, Takahide Takahashi ${ }^{2}$, Sizuma Omote ${ }^{3}$, Kenji Nishida ${ }^{3}$, \\ Takehiro Tanaka ${ }^{3}$, Daisuke Ennishi ${ }^{4}$, Fumio Otsuka ${ }^{5}$, Tadashi Yoshino ${ }^{3}$ and Hiroyuki Okada ${ }^{1}$
}

\begin{abstract}
Objective: Gastrointestinal tract lymphomas are currently detected more frequently due to advances in endoscopic technology. The aim of this study was to assess the feasibility of flow cytometric analysis of restricted light chain in endoscopic biopsy specimens for the diagnosis of gastrointestinal tract B-cell lymphoma. We prepared viable cell suspensions from unfixed specimens obtained from 10 consecutive patients who had a previous histological diagnosis of gastrointestinal tract B-cell lymphoma. We performed immunophenotypic studies with multi-color flow cytometry and assessed clonality through examination of immunoglobulin light chain expression exclusively in a population identified by anti-CD45 or CD20 antibodies.
\end{abstract}

Results: We could perform light chain expression analysis with 2 endoscopic biopsy specimens from all 10 patients with gastrointestinal tract B-cell lymphoma. We conclude that flow cytometric analysis of endoscopic biopsy specimens is feasible and thus likely useful for the diagnosis of gastrointestinal tract B-cell lymphoma in clinical settings. Trial registration UMIN Clinical Trials Registry, UMIN000027730. Registered 12 June 2017

Keywords: Flow cytometric analysis, Endoscopic biopsy specimens, Gastrointestinal tract B-cell lymphoma, Restricted light chain, Light chain expression

\section{Introduction}

Flow cytometric analysis of the lymph nodes, peripheral blood, and bone marrow is widely used for immunophenotyping of leukemia, lymphoma, myeloma, and myelodysplastic syndrome [1-3]. Although the diagnosis and classification of non-Hodgkin lymphomas are primarily made by histological examination [4], detection of clonality by flow cytometric analysis reinforces accurate diagnosis of this disease entity $[3,5]$.

The gastrointestinal tract is the most common site for extranodal B-cell lymphoma (BCL), which includes

\footnotetext{
*Correspondence: rge43gs@yahoo.co.jp

${ }^{1}$ Department of Gastroenterology and Hepatology, Okayama University Graduate School of Medicine, Dentistry and Pharmaceutical Sciences,

2-5-1 Shikata-cho, Kita-Ku, Okayama 700-8558, Japan

Full list of author information is available at the end of the article
}

marginal zone BCL, follicular lymphoma (FL), and other subsets of BCL $[6,7]$. Since almost all types of BCL show restricted light chain expression, flow cytometric analysis can theoretically be used to identify B-cell clonality by analyzing $\mathrm{K}$ and $\lambda$ ratios in a B-cell population [8]. Flow cytometric analysis of endoscopic biopsy specimens holds several potential advantages for the diagnosis of BCL. First, the number of neoplastic cells is sometimes small in biopsy specimens [9]. Although histological evaluation may be hampered owing to large amounts of normal lymphocytes in the background that obscures the lymphoma cells $[10,11]$, flow cytometric analysis is able to detect a few neoplastic cells even in a small sample [12]. Second, flow cytometric analysis requires only several hours to obtain the results, whereas histological analysis with immunostaining generally takes days to 
weeks. Early and accurate diagnosis of gastrointestinal tract BCLs by endoscopic biopsy specimens is of clinical importance to determine an appropriate treatment strategy $[13,14]$.

However, flow cytometric analysis of endoscopic biopsy specimens has not been conducted in routine clinical practice for the diagnosis of gastrointestinal tract $\mathrm{BCL}$. The aim of this study is to prospectively assess the feasibility of flow cytometric analysis of restricted light chain in endoscopic biopsy specimens for the diagnosis of gastrointestinal tract $\mathrm{BCL}$.

\section{Main text \\ Methods \\ Patients}

We performed flow cytometric analysis on ten patients with gastrointestinal tract BCLs between November 2017 and March 2018 at Okayama University Hospital and the results were analyzed prospectively. These patients had been diagnosed with lymphoma prior to flow cytometry (FCM) examination based on the histological examination of specimens obtained by endoscopic biopsy. Flow cytometric analysis was performed during the follow-up period.

\section{Pathological analysis}

We took one biopsy specimen from the lymphoma lesion using disposable biopsy forceps (EndoJaw ${ }^{\mathrm{TM}}, \mathrm{FB}-230 \mathrm{~K}$, Olympus, Tokyo, Japan) for conventional pathological analysis. The biopsy specimens were fixed in formalin and stained with Hematoxylin-Eosin. Immunostaining was also performed using a panel of monoclonal antibodies. Histological subtypes of lymphoma were defined according to the World Health Organization classification [4].

\section{Sample preparation for flow cytometric analysis}

Two additional specimens were taken from the same lesion of each patient and were used for flow cytometric analysis to analyze the expression of light chains and B-cell antigens including CD20 or CD19. Two endoscopically harvested specimens were put into a $15 \mathrm{~mL}$ conical centrifuge tube with $10 \mathrm{~mL}$ of normal saline solution. The saline solution containing specimens was decanted into a 100-mm petri dish (Dish A). Subsequently, we dissected the specimens into the finest pieces possible using a scalpel blade and tweezers. A wire mesh tea strainer, which had been sterilized by autoclaving prior to use, was placed in a new $100-\mathrm{mm}$ petri dish (Dish B). The specimen pieces were then placed on a wire mesh tea strainer and the pieces were crushed using the rubber portion of the plunger of a $10 \mathrm{~mL}$ injection syringe. Fibrous residues left on the wire mesh tea strainer were removed with tweezers. We suck up the saline solution, filtered with the wire mesh tea strainer, and poured into the $100-\mathrm{mm}$ petri dish (Dish B). Dish A was washed with a fresh saline solution, filtered through the wire mesh tea strainer, and collected into Dish B. The solution in dish B was transferred into a conical tube and centrifuged at $1500 \mathrm{rpm}$ for $5 \mathrm{~min}$ at room temperature (approximately $15^{\circ}$ ). We removed the supernatant and suspended the sample in approximately $5 \mathrm{~mL}$ of saline solution.

\section{Flow cytometric analysis}

Samples were centrifuged at $360 \mathrm{~g}$ for $5 \mathrm{~min}$ at room temperature immediately before flow cytometric analysis. After centrifugation, we removed the supernatant and resuspended with $500 \mu \mathrm{L}$ of saline solution. The solution was used for flow cytometric analysis. The monoclonal antibodies for CD45 (J33; Beckman Coulter), CD19 (J3-119; Beckman Coulter), CD20 (B-Ly1; Dako), CD10 (ALB1; Beckman Coulter), CD3 (UCHT1; Beckman Coulter), and CD5 (BL1a; Beckman Coulter) and polyclonal antibodies for surface membranes $\mathrm{K}$ (Polyclonal $\mathrm{F}\left(\mathrm{ab}^{\prime}\right) 2$; Dako) and $\lambda$ (Polyclonal $\mathrm{F}(\mathrm{ab}) 2$; Dako) were used in multi-color FCM. The immunostained cells were analyzed by FACScan (Navios flow cytometer, Beckman Coulter, Brea, CA, USA), using Kaluza analysis software version 1.3 . B-cell clonality was measured by $\kappa / \lambda$ ratios, quantifying the $\mathrm{k}$ and $\lambda$ light chain expressions in a gated CD45 population (CD45+ cell population) or a gated CD20 population (CD20+ cell population). The primary outcome of this study was the feasibility of flow cytometric analysis to detect the expression of light chains in the 2 biopsy specimens, which were endoscopically taken from patients with gastrointestinal tract BCLs. We also examined patients' clinicopathologic features based on their medical records, including the gender, age, site of primary gastrointestinal tract BCLs, histological subtype, chromosomal aberration, stage based on the Lugano International Conference classification, incidence of $\mathrm{Heli}$ cobacter pylori infection, and treatment.

\section{Results \\ Patient characteristics}

The characteristics of 10 patients, who were previously diagnosed with gastrointestinal tract BCL based on the histological examination of endoscopic biopsy specimens, are shown in Table 1 . Three were males and 7 were females, and the median age was 68.5 years (range 50s80 s years). The histological subtypes were gastric extranodal marginal zone lymphoma of mucosa-associated lymphoid tissue (MALT lymphoma, $\mathrm{N}=7$ ) and duodenal $\mathrm{FL}$, grade $1(\mathrm{~N}=3)$. All 10 patients had stage I disease. 


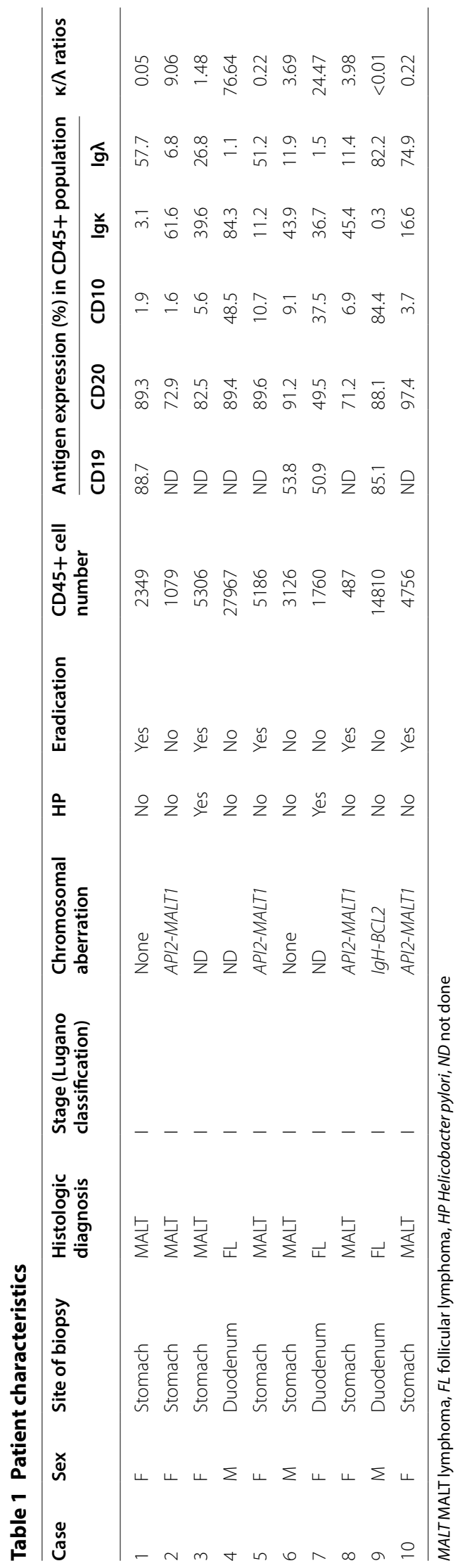




\section{Pathological analysis}

As described above, we endoscopically took three specimens from the lymphoma lesion with disposable biopsy forceps; one biopsy specimen was provided for conventional pathological analysis and the other two specimens were used for flow cytometric analysis. Pathology of the biopsy specimen were in accordance with the previous histological diagnosis in all cases.

\section{Flow cytometric analysis}

For flow cytometric analysis, 487 to 27,967 CD $45+$ cells (median: 3941 cells) were analyzed. In seven patients, more than $80 \%$ of the CD45+ cells expressed the B-cell antigen (CD20 or CD19). In MALT lymphomas, $1.6 \%$ to $10.7 \%$ of CD $45+$ cells were positive for CD10, whereas $37.5 \%$ to $84.4 \%$ of CD 45 + cells were positive for CD10 in FLs. The light chain expression was successfully analyzed in all 10 patients (100\%) by flow cytometric analysis.

\section{Representative results of flow cytometric analysis}

Figure 1 (gastric MALT lymphoma, case 2) and 2 (duodenal FL, case 9) show representative results of flow cytometric analysis, in which clonal B-cell populations were detectable. In Fig. 1, 23.76\% of isolated cells were positive for CD45 (Fig. 1a, gate A). Among the CD 45+ cell populations, $72.89 \%$ of the cells were CD20+ (Fig. 1b). Light chain expression analysis showed dominant Igk expression, resulting in $\kappa / \lambda$ ratio of 9.06 . These results were suggestive of clonal B-cells. In Fig. 2, 84.62\% of the isolated cells displayed CD45 expression (Fig. 2a, gate A). CD19+ and CD10+ cells were found in $85.14 \%$ and $84.38 \%$ of the CD $45+$ cells, respectively (Fig. $2 b$ ). Dominant Ig $\lambda$ expression with $\kappa / \lambda$ ratio of 0.0036 was observed, indicating the presence of clonal B-cells (Fig. 2c).

\section{Better selection of clonal B-cells}

Additional file 1: Fig. S1 (gastric MALT lymphoma, case 6) shows a case, in whom a subpopulation of cells with slightly decreased CD45 expression is evident.
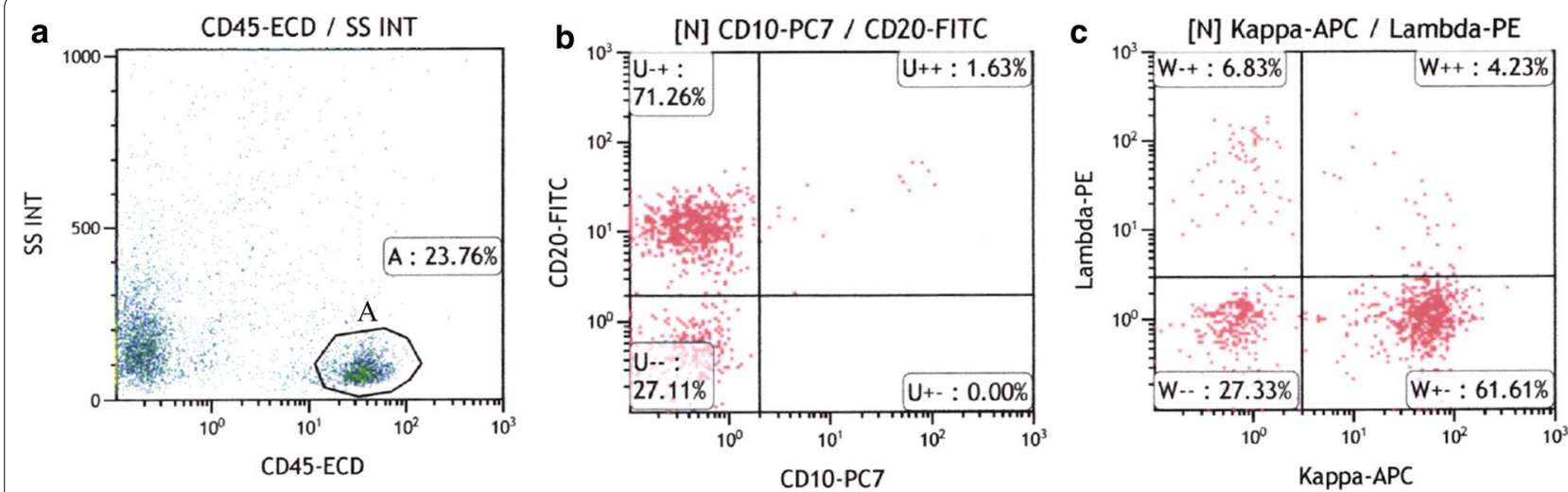

Fig. 1 (Case 2) Flow cytometric analysis showing B-cell lymphomas. a Isolated cells (23.76\%) (gate A) were positive for CD45. b Among the CD45+ cell populations, $72.89 \%$ of the cells were CD20+. $\mathbf{c}$ Light chain expression analysis showed dominant Igk expression, resulting in $\mathrm{k} / \lambda$ ratio of 9.06
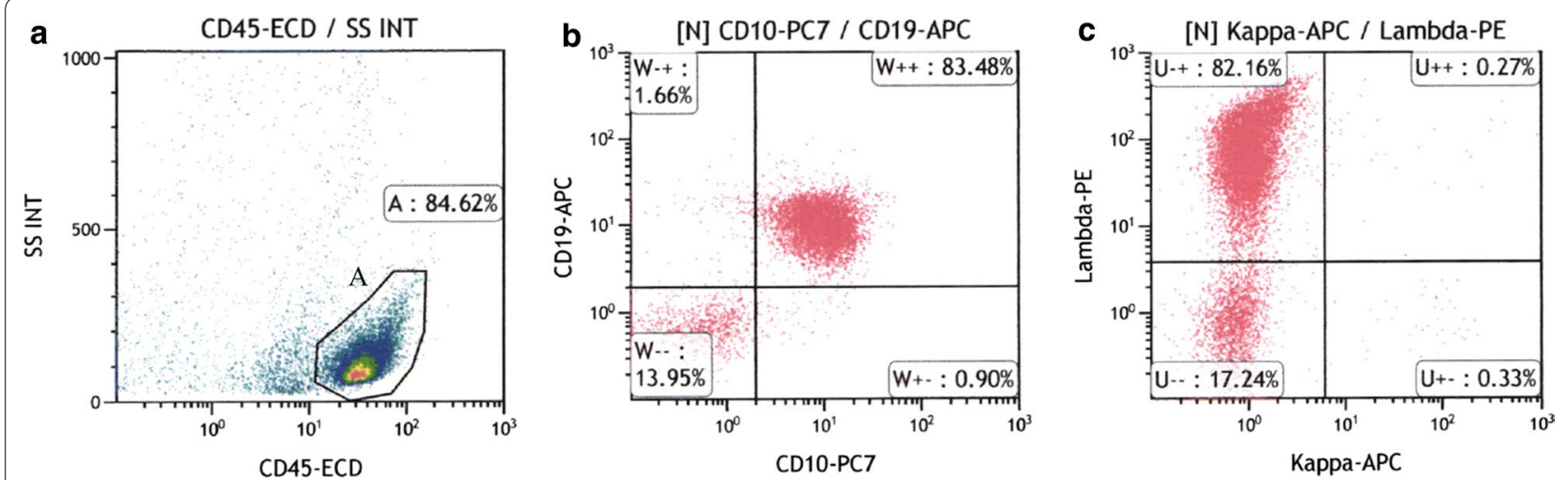

Fig. 2 (Case 9) Flow cytometric analysis showing B-cell lymphomas. a Isolated cells (84.62\%) (gate A) showed CD45 expression. b CD19+ and $\mathrm{CD} 10+$ cells were found in $85.14 \%$ and $84.38 \%$ of the CD $45+$ cells, respectively. $\mathbf{c}$ Dominant Ig $\lambda$ expression with $\mathrm{k} / \lambda$ ratio of 0.0036 was observed 
In Additional file 1: Fig. S1, 41.80\% of the isolated cells showed CD45 expression (Additional file 1: Fig. S1A, gate A). Light chain expression analysis of gate A showed dominant Igk expression with $\kappa / \lambda$ ratio of 3.69 (Additional file 1: Fig. S1B). Analysis of subpopulation of cells with slightly decreased CD45 expression (Additional file 1: Fig. S1A, gate B) revealed more dominant Igk expression with $\kappa / \lambda$ ratio of 7.30 (Additional file 1 : Fig. S1C), suggesting better selection of clonal B-cells. We performed the subpopulation analysis in the other 3 cases (cases 1, 5, and 7) and observed slightly more dominant light chain expression than in a CD45+ cell population (Additional file 2: Table S1).

\section{Discussion}

In this study, we successfully performed light chain expression analysis with 2 endoscopic biopsy specimens from each of all 10 patients, although previous studies reported that an adequate number of cells in endoscopic biopsy specimens are essential for flow cytometric analysis $[15,16]$. These CD45+ cells also allowed us to perform a limited but common immunophenotypic study, including the simultaneous analysis of light chain, CD20 or CD19, and CD10 antigen expression in each case.

Given that the previously published criteria for flow cytometric analysis of restricted light chain (normal range $0.5-3.0$, any values outside this range are regarded as restricted light chain $[3,5,17])$ were applied to the endoscopic biopsy specimens in our study, $90 \%$ of the patients ( 9 of 10 patients) displayed restricted light chain expression, consistent with $\mathrm{BCL}$, while one patient (case 3) did not. Several hypotheses are considered for the lack of restricted light chain expression. First, inadequate samples, owing to non-representative sampling or nonviable neoplastic cells, may lead to a false-negative result by flow cytometric analysis. Second, the existence of B cells with negative or dual positive expressions of $\mathrm{K}$ and $\lambda$ results in inconclusive restricted light chain expression analysis [18-20], despite the presence of neoplastic B-cells. In case $3,8.1 \%$ of CD45+ cells were positive for both $\kappa$ and $\lambda$ and $25.5 \%$ of CD45+ cells were negative for $\kappa$ and $\lambda$. Both percentages were higher than with any other cases. Therefore, the diversity of light chain expression among neoplastic B cells might have distorted analysis. Thirdly, the gating of B-cells, due to aberrant B-cell surface antigen expression by the lymphoma, was inappropriate, and therefore immunoglobulin light chain expression may not be detected.

CD45 is a marker of lymphocytes [21]. Hendrickx et al. investigated CD45 expression of normal B lymphocytes $(\mathrm{N}=15)$, chronic lymphocytic leukemia $(\mathrm{N}=22)$, mantle cell lymphoma $(\mathrm{N}=2)$, and hairy cell leukemia $(\mathrm{N}=6)$. The authors described that neoplastic B-cells in chronic lymphocytic leukemia and mantle cell lymphoma showed slightly decreased CD45 expression, whereas those in hairy cell leukemia showed slightly higher CD45 expression. Previously, we also reported a case of gastric MALT lymphoma, in which neoplastic B-cells were successfully separated by identifying a subpopulation of cells with slightly decreased CD45 expression [22]. In case 6, light chain expression analysis of the slightly decreased CD45+ cell subpopulation showed more dominant Igk expression with $\kappa / \lambda$ ratio of 7.30 (Additional file 1: Fig. $\mathrm{S} 1 \mathrm{C})$. Light chain expression analysis of the other 3 cases also showed slightly more dominant light chain expression, as described in Additional file 2: Table S1. We speculate that identifying a subpopulation of cells with slightly decreased CD45 expression may be useful for improving the accuracy of differential diagnoses between neoplastic B-cells (lymphoma cells) and the other cells (non-lymphoma cells), such as reactive inflammatory lymphoid changes.

CD10 is a proteolytic enzyme expressed on the surface of germinal center B-cells and lymphomas derived from these cells, that is, FL $[23,24]$. A cut-off value of $20 \%$ is used to judge CD10 positivity [25]. In the present study, all FL cases were positive (>20\%) and MALT lymphoma cases were negative for CD10 $(\leq 20 \%)$. These results are consistent with previous reports.

In conclusion, we could perform flow cytometric analysis with only 2 endoscopic biopsy specimens from the gastrointestinal tract. We consider that flow cytometric analysis of endoscopic biopsy specimens is feasible, and thus likely useful, for the diagnosis of gastrointestinal tract BCL in clinical settings.

\section{Limitations}

- This was a prospective study involving a small number of patients conducted at a single center.

- Although the criteria for flow cytometric analysis of restricted light chain has been proposed for lymph nodes or bone marrow-derived B-cells, there have been no criteria for endoscopic biopsy specimens from patients with gastrointestinal tract BCL.

\section{Supplementary information}

Supplementary information accompanies this paper at https://doi. org/10.1186/s13104-019-4578-4.

Additional file 1: Fig S1. Better selection of clonal B-cells by a subpopulation of cells with slightly decreased CD45 expression on Case 6. A Isolated cells (41.80\%) (gate A) showed CD45 expression. B Light chain expression analysis of gate $A$ showed dominant lgk expression with $k / \lambda$ ratio of 3.69. C Analysis of subpopulation of cells with slightly decreased CD45 
expression (gate $B$ ) revealed more dominant lgk expression with $\mathrm{k} / \lambda$ ratio of 7.30 .

Additional file 2: Table S1. Comparison between a slightly decreased CD45+ and a CD45+ cell population. Light chain expression analysis showed more dominant light chain expression in a slightly decreased CD45+ cell population than in a CD45+ cell population.

\section{Abbreviations}

FCM: flow cytometry; BCL: B-cell lymphoma; FL: follicular lymphoma.

\section{Acknowledgements}

The author thanks Ms. Hiromi Nakashima, Department of Hematology and Oncology, Okayama University Graduate School of Medicine, Dentistry and Pharmaceutical Sciences, for technical assistance.

\section{Authors' contributions}

$\mathrm{KM}$ and $\mathrm{MI}$ conceived the study; TT analysed the data and generated the results; $\mathrm{SO}, \mathrm{KN}, \mathrm{TT}, \mathrm{DE}, \mathrm{FO}, \mathrm{TY}$ and $\mathrm{HO}$ contributed in revising the obtained results; KM wrote the manuscript. All authors read and approved the final manuscript.

\section{Funding}

Not applicable.

\section{Availability of data and materials}

The datasets used and analysed during the current study are available from the corresponding author on reasonable request.

\section{Ethics approval and consent to participate}

Patients were prospectively registered and analyzed in this study. Biopsy sampling and flow cytometric analyses were performed as part of the standard clinical practice. Thus, written informed consent was waived for enrollment. This study was approved by the ethics committee of Okayama University Hospital and adhered to the principles of the Declaration of Helsinki. The study protocol was registered in the UMIN Clinical Trials Registry (UMIN000027730).

\section{Consent for publication}

Not applicable.

\section{Competing interests}

The authors declare that they have no competing interests.

\begin{abstract}
Author details
${ }^{1}$ Department of Gastroenterology and Hepatology, Okayama University Graduate School of Medicine, Dentistry and Pharmaceutical Sciences, 2-5-1 Shikata-cho, Kita-Ku, Okayama 700-8558, Japan. ${ }^{2}$ Division of Medical Support, Okayama University Hospital, Okayama 700-8558, Japan. ${ }^{3}$ Department of Pathology, Okayama University Graduate School of Medicine, Dentistry and Pharmaceutical Sciences, Okayama 700-8558, Japan. ${ }^{4}$ Department of Hematology and Oncology, Okayama University Graduate School of Medicine, Dentistry and Pharmaceutical Sciences, Okayama 700-8558, Japan. ${ }^{5}$ Department of General Medicine, Okayama University Graduate School of Medicine, Dentistry and Pharmaceutical Sciences, Okayama 700-8558, Japan.
\end{abstract}

Received: 29 May 2019 Accepted: 21 August 2019

Published online: 11 September 2019

\section{References}

1. Gu J, Huh YO, Jiang F, Caraway NP, Romaguera JE, Zaidi TM, Fernandez RL, Zhang H, Khouri IF, Katz RL. Evaluation of peripheral blood involvement of mantle cell lymphoma by fluorescence in situ hybridization in comparison with immunophenotypic and morphologic findings. Mod Pathol. 2004;17(5):553-60.
2. Liendo C, Danieu L, Al-Katib A, Koziner B. Phenotypic analysis by flow cytometry of surface immunoglobulin light chains and B and T cell antigens in lymph nodes involved with non-Hodgkin's lymphoma. Am J Med. 1985;79(4):445-54.

3. Kawano-Yamamoto C, Muroi K, Izumi T, Saito K, Ozawa K. Twocolor flow cytometry with a CD19 gate for the evaluation of bone marrow involvement of B-cell lymphoma. Leukem Lymphoma. 2002;43(11):2133-7.

4. Swerdlow S, Campo E, Harris N, Jaffe E, Pileri S, Stein H, Thiele J, Vardiman J. World Health Organization classification of tumours of haematopoietic and lymphoid tissues. Geneva: WHO; 2008.

5. Geary WA, Frierson HF, Innes DJ, Normansell DE. Quantitative criteria for clonality in the diagnosis of B-cell non-Hodgkin's lymphoma by flow cytometry. Modern Pathol. 1993;6(2):155-61.

6. Burke JS. Lymphoproliferative disorders of the gastrointestinal tract: a review and pragmatic guide to diagnosis. Arch Pathol Lab Med. 2011;135(10):1283-97.

7. Papaxoinis G, Papageorgiou S, Rontogianni D, Kaloutsi V, Fountzilas G, Pavlidis N, Dimopoulos M, Tsatalas C, Xiros N, Economopoulos T. Primary gastrointestinal non-Hodgkin's lymphoma: a clinicopathologic study of 128 cases in Greece. A Hellenic Cooperative Oncology Group study (HeCOG). Leukem Lymphoma. 2006;47(10):2140-6.

8. Batata A, Shen B. Diagnostic value of clonality of surface immunoglobulin light and heavy chains in malignant lymphoproliferative disorders. Am J Hematol. 1993;43(4):265-70.

9. Wotherspoon AC, Doglioni C, Diss TC, Pan L, Moschini A, de Boni M, Isaacson PG. Regression of primary low-grade B-cell gastric lymphoma of mucosa-associated lymphoid tissue type after eradication of Helicobacter pylori. Lancet (London, England). 1993;342(8871):575-7.

10. Arista-Nasr J, Jimenez A, Keirns C, Larraza O, Larriva-Sahd J. The role of the endoscopic biopsy in the diagnosis of gastric lymphoma: a morphologic and immunohistochemical reappraisal. Hum Pathol. 1991;22(4):339-48.

11. Zukerberg LR, Ferry JA, Southern JF, Harris NL. Lymphoid infiltrates of the stomach. Evaluation of histologic criteria for the diagnosis of low-grade gastric lymphoma on endoscopic biopsy specimens. Am J Surg Pathol. 1990;14(12):1087-99.

12. Demurtas A, Accinelli G, Pacchioni D, Godio L, Novero D, Bussolati G, Palestro G, Papotti M, Stacchini A. Utility of flow cytometry immunophenotyping in fine-needle aspirate cytologic diagnosis of non-Hodgkin lymphoma: a series of 252 cases and review of the literature. Appl Immunohistochem. 2010;18(4):311-22.

13. Fisher RI, Dahlberg S, Nathwani BN, Banks PM, Miller TP, Grogan TM. A clinical analysis of two indolent lymphoma entities: mantle cell lymphoma and marginal zone lymphoma (including the mucosa-associated lymphoid tissue and monocytoid B-cell subcategories): a Southwest Oncology Group study. Blood. 1995;85(4):1075-82.

14. Cogliatti SB, Schmid U, Schumacher U, Eckert F, Hansmann ML, Hedderich J, Takahashi H, Lennert K. Primary B-cell gastric lymphoma: a clinicopathological study of 145 patients. Gastroenterology. 1991;101(5):1159-70.

15. Oka S, Muroi K, Sato K, Fujiwara S, Oh I, Matsuyama T, Ohmine K, Suzuki T, Ozaki K, Mori M, et al. Flow cytometric analysis of kappa and lambda light chain expression in endoscopic biopsy specimens before the diagnosis of B-cell lymphoma. J Clin Exp Hematopathol. 2012;52(2):127-31.

16. Almasri NM, Zaer FS, Iturraspe JA, Braylan RC. Contribution of flow cytometry to the diagnosis of gastric lymphomas in endoscopic biopsy specimens. Modern Pathol. 1997;10(7):650-6.

17. Gunduz E, Celebioglu M, Meltem Akay O, Uskudar Teke H, Sahin Mutlu F, Gulbas Z. The role of flow cytometry in the diagnosis of non- Hodgkin's lymphoma, Hodgkin's lymphoma, granulomatous inflammation and reactive lymph node specimens. J BUON. 2013;18(3):739-45.

18. Xu D. Dual surface immunoglobulin light-chain expression in B-cell lymphoproliferative disorders. Arch Pathol Lab Med. 2006;130(6):853-6.

19. Li S, Eshleman JR, Borowitz MJ. Lack of surface immunoglobulin light chain expression by flow cytometric immunophenotyping can help diagnose peripheral B-cell lymphoma. Am J Clin Pathol. 2002;118(2):229-34.

20. Kaleem Z, Zehnbauer BA, White G, Zutter MM. Lack of expression of surface immunoglobulin light chains in B-cell non-Hodgkin lymphomas. Am J Clin Pathol. 2000;113(3):399-405.

21. HendrickX A, Bossuyt X. Quantification of the leukocyte common antigen (CD45) in mature B-cell malignancies. Cytometry. 2001;46(6):336-9. 
22. Matsueda K, Omote S, Sakata M, Fujita I, Horii J, Toyokawa T. The diagnosis of gastric mucosa-associated lymphoid tissue lymphoma by flow cytometry and fluorescence in situ hybridization of biopsy specimens. Intern Med (Tokyo, Japan). 2017;57:1081-6.

23. Barcus ME, Karageorge LS, Veloso YL, Kornstein MJ. CD10 expression in follicular lymphoma versus reactive follicular hyperplasia: evaluation in paraffin-embedded tissue. Appl Immunohistochem. 2000;8(4):263-6.

24. Almasri NM, Iturraspe JA, Braylan RC. CD10 expression in follicular lymphoma and large cell lymphoma is different from that of reactive lymph node follicles. Arch Pathol Lab Med. 1998;122(6):539-44.
25. Muroi K, Suda T, Kawano C, Amemiya Y, Eguchi M, Miura Y, Ozawa K. Analysis of C-KIT, TIE and HTK expression on leukemic cells using flow cytometry: a preliminary report. Leuk Res. 1998;22(9):827-30.

\section{Publisher's Note}

Springer Nature remains neutral with regard to jurisdictional claims in published maps and institutional affiliations.
Ready to submit your research? Choose BMC and benefit from:

- fast, convenient online submission

- thorough peer review by experienced researchers in your field

- rapid publication on acceptance

- support for research data, including large and complex data types

- gold Open Access which fosters wider collaboration and increased citations

- maximum visibility for your research: over 100M website views per year

At BMC, research is always in progress.

Learn more biomedcentral.com/submissions 